\title{
Mini-Gastric Bypass as a Second Bariatric Surgery for Nutritional Problems of Restrictive Surgery
}

\author{
Islam H ElAbbassy, ${ }^{1}$ MD; Hatem Elgohary ${ }^{2}$ MD \\ ${ }^{1}$ General Surgery Department, Ain Shams University, Egypt \\ ${ }^{2}$ General Surgery Department, Helwan University, Egypt
}

The purpose of this study was to evaluate mini-gastric bypass (MGB) as a second bariatric procedure for patients with behavioral nutritional problems after primary restrictive procedures, with special emphasis on operative and postoperative outcomes.

Patients and methods: This was a prospective cohort study that was conducted in the Department of General Surgery at Ain Shams University Hospital from 2012 to 2014, where laparoscopic mini-gastric bypass (MGB) was performed in 30 consecutive patients with nutritional behavior problems after restrictive surgery. The outcome of surgery was assessed at 3,6,9 and 12 months for correction of nutritional behavior problems, as well as the body mass index (BMI). Nutritional deficiencies due to MGB were monitored.

Results: MGB was successful in prevention of vomiting and correction of solid food intolerance in 27 (90\%) out of the 30 patients. The sweet eating behavior was corrected in all patients but new nutritional problems in the form of dumping and bilious vomiting were reported. Weight loss results were very satisfactory after one year.

Conclusion: MGB is a good successful second procedure in correction of nutritional problems arising after primary restrictive surgery. Both solid food intolerance and sweet eating were successfully corrected. There was also a very satisfactory improvement in weight loss results.

Keywords: Mini-gastric bypass, laparoscopic bariatric surgeries, nutritional problems, body mass index, biliary reflux.

\section{Introduction}

The normal physiology of digestion is minimally affected by restrictive bariatric surgical procedures such as gastric banding (GB), vertical banded gastroplasty (VBG) and sleeve gastrectomy (SG). Consequently, nutritional deficiencies are uncommon to occur with such procedures. However, nutritional deficiencies can occur due to caloric restriction and inadequate nutritional behaviors. This is common with rapid and significant loss of weight. ${ }^{1}$ The limited volume capacity after gastric restriction causes a marked reduction in the amount of food eaten at each meal and this is the main mechanism of losing weight in those patients. ${ }^{2}$

All experts recommend that postoperatively patients should have small frequent meals, food should be chewed well, beverages should be taken after 30 minutes of having a meal, and not at the same time, and they should also stop eating once they are full. Patients also need to eat more fruits and vegetables, while food that is rich in saturated fats and simple carbohydrates should be limited. ${ }^{2}$ Failure to follow these nutritional instructions would end up with failure of these restrictive procedures and a second bariatric procedure might be needed. Intolerance for solid food, vomiting and sweet eating are the commonest problems that have influence on the lifestyle of people trying to lose weight. These are considered good indications for having a second surgery. Mini-gastric bypass (MGB) that was described by Rutledge, 3 was found to have excellent outcomes as a malabsorptive bariatric surgery, with low rates of complications. ${ }^{4-9}$

The purpose of this study was to evaluate MGB as a second bariatric procedure for patients with behavioral nutritional problems after primary restrictive procedures, with special emphasis on operative and postoperative outcomes.

\section{Patients and methods}

This was a prospective cohort study that was conducted in the Department of General Surgery at Ain Shams University Hospital from 2012 to 2014 (after having the IRB approval) where MGB was performed in 30 consecutive patients with nutritional behavior problems after previous restrictive surgery. Eighteen patients of them had a previous VBG, 8 had GB and 4 patients had SG.

Full history was taken from patients (including type of surgery previously performed and whether there were associated symptoms of solid food 
intolerance, vomiting or sweet eating) and their BMI was calculated. Pre-operative nutritional assessment was done through a questionnaire filled in by the patients and an informed written consent was signed.

The surgery was done laparoscopicaly for all patients under general anesthesia. Patients lied supine with separated legs and elastic stockings were used as a prophylaxis for DVT. A Veress needle was inserted in the left subcostal region with strong upward skin retraction to create the pneumoperitoneum. A $12 \mathrm{~mm}$ camera port was introduced in the midline at $1 / 3$ the distance between the umbilicus and the xiphisternum then a 30 degree-angled scope was put through it to direct other port placement. Two $12 \mathrm{~mm}$ working ports were inserted in the midclavicular plane on either side of the midline, Another $10 \mathrm{~mm}$ port was inserted in the left upper quadrant to help retract the gastric fundus and a last $10 \mathrm{~mm}$ port to help liver retraction was placed to the left and just below the xiphoid process.

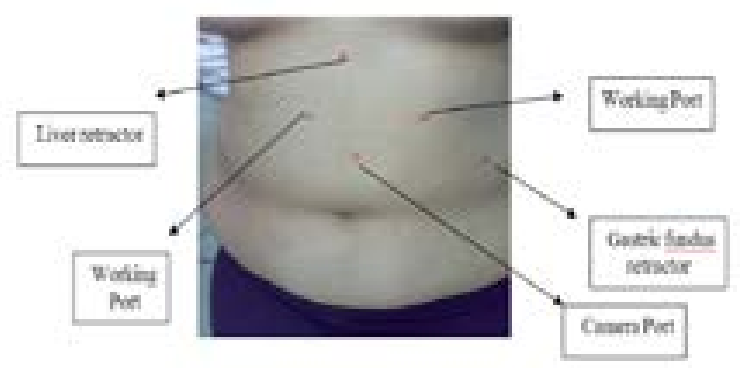

Fig 1: The port sites for MGP.

Patients were then placed in steep reverse Trendelenburg position to expose the esophagus and stomach.

A long narrow gastric tube was created by using staplers (45 mm and $60 \mathrm{~mm}$ Endo GIA linear staplers) after withdrawing the nasogastric tube up into the esophagus to avoid being caught by the staplers.

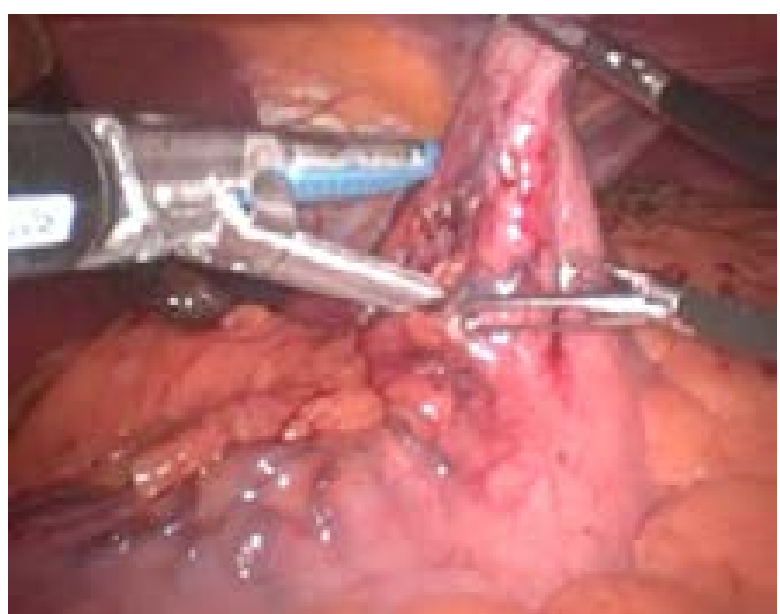

Fig 2: Creation of gastric tube.

The omentum was then opened from the free border till the transverse colon to form the omental curtain and to identify the duodeno-jejunal flexure (DJ). The jejunal loop was drawn upwards through the omental curtain in front of the body of the stomach towards the gastric tube.

This was followed by subsequent anastomosis of that gastric tube to the jejunal loop, at about 200 $\mathrm{cm}$ from the DJ using a $45 \mathrm{~mm}$ Endo GIA linear stapler to create the gastrojejunostomy side to side anastomosis. The site of insertion of the stapler was then closed using continuous $2 / 0$ polygalactin sutures. Intra-operative testing of the stapler line was done by injecting diluted methylene blue dye through the nasogastric tube to exclude any leaks. The mesenteric defect was then closed using 2/0 polypropylene purse string sutures. A drain was placed posterior to the gastrojejunal anastomosis and brought out through the right subcostal port site.

Prophylactic antithrombotic measures (anticoagulant therapy, elastic stocking, pneumatic pressure garments and leg massage) and antibiotics were continued until patients got ambulant. Oral diet was started on the third post-operative day. Patients started on daily multivitamins 3 weeks after surgery.

On postoperative day 4, most patients were discharged home on liquid diet for 2 weeks with about $100 \mathrm{ml}$ of fluid given every hour. Low fat and low calorie fluids as milk, yogurt, fruits or vegetable juices and warm soups were advised. For the next two weeks, feeding was built up to pureed food. Meals were not given more than $100-150 \mathrm{gm}$ at a time. The total amount of purred food was around $500 \mathrm{gm} /$ day, and then small portions of normal food were given for two weeks. After that, patients were asked to make up their own menus, they were advised to eat little and chew the food thoroughly. Drinking was allowed 
only between meals. Written instructions were given to each patient.

Outcome of the surgery was assessed at 3, 6, 9 and 12 months for correction of nutritional behavior problems, as well as for calculating the BMI. Nutritional deficiencies due to MGB were monitored.

\section{Results}

There were 10 male (33.3\%) and 20 female patients $(66.6 \%)$ with a mean age of 32.17 years. The mean BMI before revision was 39.46. The mean interval between the last bariatric surgery and the MGB was 35.45 months.

The pre-operative nutritional assessment questionnaire showed that all selected patients $(100 \%)$ were having solid food intolerance. There was an overlap between solid food intolerance, vomiting and sweet eating in 25 patients (83.3\%) (Table 1).

Table 1: Pre-operative data of patients with previous VBG, GB and SG before being operated upon by MGB

\begin{tabular}{|c|c|c|c|}
\hline & VBG & GB & SG \\
\hline Number & $\begin{array}{c}18 \\
\text { cases }\end{array}$ & 8 cases & 4 cases \\
\hline Mean age (years) & 28.28 & 37.66 & 30.57 \\
\hline $\begin{array}{l}\text { Mean pre-operative BMI } \\
\left(\mathrm{Kg} / \mathrm{m}^{2}\right)\end{array}$ & 38.2 & 40.75 & 39.44 \\
\hline Solid food intolerance & $\begin{array}{c}18 \\
\text { cases }\end{array}$ & 8 cases & 4 cases \\
\hline Vomiting & $\begin{array}{c}18 \\
\text { cases }\end{array}$ & 6 cases & 1 case \\
\hline Sweet eating & $\begin{array}{c}16 \\
\text { cases }\end{array}$ & 6 cases & 3 cases \\
\hline $\begin{array}{l}\text { Mean time interval from } \\
\text { the previous bariatric } \\
\text { procedure (months) }\end{array}$ & 38.6 & 32.55 & 35.2 \\
\hline
\end{tabular}

Comparison between patients with prior VBG, SG and GB showed that the mean operative time and postoperative hospital stay was longer in patients with previous VBG. Moreover, we recorded one case of dumping (3.3\%) and another case of occasional bilious vomiting $(3.3 \%)$ in patients with previous VBG. These were corrected by educating the patients to eat slowly, avoid eating before sleep and by giving proton pump inhibitors. There was only one case $(3.3 \%)$ of malnutrition and anemia in patients with prior SG that was corrected by adequate iron and vitamin supplementation.

Conversion to open was not required in any of the patients. No mortalities occurred in this series.
Table 2: Operative time, hospital stay and complications of MGP for the three groups of selected patients

\begin{tabular}{lccc}
\hline & VBG & GB & SG \\
\hline $\begin{array}{l}\text { Mean operative time } \\
\text { (minutes) }\end{array}$ & 182.88 & 154.12 & 110.99 \\
Mean hospital stay (days) & 5.12 & 4.09 & 3.01 \\
Dumping & 1 & - & - \\
Bilious vomiting & 1 & - & - \\
Malnutrition and anemia & - & & 1 \\
\hline
\end{tabular}

MGB was successful in prevention of vomiting, correction of solid food intolerance in $27(90 \%)$ out of the 30 patients. The sweet eating behavior was corrected in all patients $(100 \%)$ and weight loss results were very satisfactory at 12 months.

The mean BMI showed a progressive decrease in the first 9 months after surgery that was followed by only a trivial decrease in the following 3 months, and by the end of the follow up period, patients reached a satisfying BMI without excessive weight loss. All patients were satisfied with the eating dimension and were able to eat solid well-chewed food.

Table 3: Follow up of BMI postoperatively

\begin{tabular}{lccc}
\hline & VBG & GB & SG \\
\hline $\begin{array}{l}\text { Mean BMI after } 3 \\
\text { months }\left(\mathrm{kg} / \mathrm{m}^{2}\right)\end{array}$ & 32.8 & 35.2 & 34.25 \\
$\begin{array}{l}\text { Mean BMI after } 6 \\
\text { months }\left(\mathrm{kg} / \mathrm{m}^{2}\right)\end{array}$ & 29.96 & 31.22 & 30.26 \\
$\begin{array}{l}\text { Mean BMI after } 9 \\
\text { months }\left(\mathrm{kg} / \mathrm{m}^{2}\right)\end{array}$ & 27.57 & 28.79 & 27.99 \\
$\begin{array}{l}\text { Mean BMI after } 12 \\
\text { months }\left(\mathrm{kg} / \mathrm{m}^{2}\right)\end{array}$ & 27.24 & 27.55 & 27.82 \\
\hline
\end{tabular}

\section{Discussion}

Good food tolerance was defined by Schweiger $C$ et al. as the capability to eat various types of food easily, such as red meat, white meat, salad, vegetables, bread, rice, pasta, and fish. This study showed that impaired eating quality and food intolerance usually develop after all types of bariatric surgeries; however, tolerance gets better by passing of time and is affected by the type of surgery. They found that patients with LAGB had the lowest quality of eating in comparison with Roux-en-Y gastric bypass (RYGB), SG, and biliopancreatic diversion (BPD) patients. ${ }^{10}$

In our study, the pre-operative nutritional assessment questionnaire showed that the 30 selected patients $(100 \%)$ were having solid food intolerance after previous bariatric procedure, whereas vomiting and sweet eating occurred 
in 25 patients (83.3\%). Suter et $\mathrm{al}^{11}$ found that LAGB patients had lower food tolerance in comparison to RYGB patients immediately after surgery. A study conducted by De Zwaan et al, ${ }^{12}$ on 59 patients that underwent RYGB revealed that $30.5 \%$ of them complained of constant chewing and spitting out food to avoid plugging, and over $60 \%$ reported to have attacks of vomiting 18 to 35 months following the operation. However, the results of our study showed that MGB was successful in preventing vomiting and that solid food intolerance was corrected in 27 patients $(90 \%)$ out of the 30 and patients were satisfied with the eating dimension and were able to eat solid well-chewed food. The sweet eating behavior was corrected in all patients (100\%) and weight loss results were very satisfactory at 12 months.

Ernst B et al. in their study showed that repeated vomiting and avoiding eating certain types of foods might result in shifting of some patients to eat soft and semi liquid high-caloric diet that might allow them to eat larger portions and avoid vomiting. This behavior might end up with an unexpected putting on weight. ${ }^{13}$ Moreover, the incapacity to eat different types of food and frequent vomiting could also result in nutritional deficiencies. ${ }^{10}$

Many studies have described RYGB to be the best procedure for revision. ${ }^{14-17}$ However, complete dissection of the upper stomach and performing an anastomosis close to the esophago-gastric junction would make this procedure very challenging, especially in cases with band erosion that have marked adhesions as a result of the massive inflammatory process. Furthermore, the high site of anastomosis would make it more liable for tension and fistula formation. ${ }^{18}$ In contrast, MGB has a lower anastomosis and complete dissection of the upper part of the stomach is not mandatory. Moreover, the Roux-en-Y limb is dispensed in MGP by creating a long gastric tube with one less anastomosis that provides better blood supply to the gastric tube, which might decrease the incidence of leakage and makes the procedure easier. ${ }^{19}$

In our study, we did not report any cases of anastomotic leakage. The issue of whether increased bile acid in the stomach might result in developing chronic gastritis and inducing carcinogenic effects after MGB has aroused much controversy. ${ }^{20}$ The incidence of bilious vomiting and gastritis was reported to be $70 \%$ after Mason's old loop gastric bypass; this is because of its high transverse small pouch and having a loop close to the esophagus. ${ }^{21,22}$ Therefore, Rouxen- $Y$ construction in gastric bypass was used to decrease the incidence of reflux alkaline esophagitis. However, bile reflux is not considered to be a common complication in MGB as the anastomosis is low in the stomach. ${ }^{23-25}$ However, patients may experience bile reflux occasionally, especially during vomiting. In our study there was only one patient $(3.3 \%)$ with bilious vomiting that resolved after few days by giving proton pump inhibitors and by avoiding eating before sleeping. In a study done by Mahawar KK et al. the incidence of bile reflux and marginal ulcers in MGB has been reported to be very low and similar to that in Roux-en-Y gastric bypass, ${ }^{26}$ whereas in the series done by Noun et al. on 1,000 patients in 6 years, only 4 patients $(0.4 \%)$ required revision of MGB due to bile reflux and were operated on by laparoscopic latero-lateral (Braun) jejunojejunostomy. ${ }^{27}$

Development of marginal ulcer is a possible complication of MGB. It is usually transient and could be treated by proton pump inhibitors. To avoid development of marginal ulcer, it is essential to create a narrow gastric tube during performing the operation. The development of marginal ulcer is usually related to the size of the gastric tube and the consumption of drugs that predispose to ulceration. ${ }^{7}$

However, in our study, we did not report any marginal ulcers during the period of follow up. In terms of weight loss, our results showed that the mean BMI decreased progressively in the first 9 months after surgery then the rate of decrease slowed down and by the end of the follow up period, a satisfying BMI was reached without excessive weight loss.

Some studies showed that more weight loss would be obtained by increasing the length of the bypassed small intestinal limb but, at the same time, this would increase the incidence of late nutritional deficiencies such as iron deficiency anemia, vitamin B deficiency, folate deficiency, and other micronutrient deficiencies. Anemia that could develop with gastric bypass could be remedied by giving adequate iron and vitamin supplements. However, detection of long-term sequelae of micronutrient deficiencies, such as bone disease, needs further long-term follow-up. ${ }^{28-30}$ Mahawar KK et al. in their study suggested that adjusting the bypass limb in MGB according to the BMI may give a chance to balance between weight reduction and the risk of developing micronutrient deficiencies. They declared that better results could be obtained by using a bypass limb of $150 \mathrm{~cm}$ in patients with BMI below 40, with increasing $10 \mathrm{~cm}$ in that limb with every BMI category related to obesity instead of using a fixed $200-\mathrm{cm}$ limb for all patients. ${ }^{26}$ In our study there was only one case (3.3\%) of malnutrition and anemia that was corrected by iron and vitamin 
supplementation, whilst in a study done by Kular KS et al., ${ }^{31}$ anemia was seen in $6.9 \%$ of MGB patients at 5 years. Similar incidence was detected in studies conducted by Lee et al., Rutledge and Walsh, and Rutledge. .,8,32 $^{2}$

\section{Conclusion}

MGB is a good successful second procedure in correction of nutritional problems arising after primary restrictive surgery. Both solid food intolerance and sweet eating are successfully corrected. There is also a very satisfactory improvement in weight loss results.

\section{References}

1. Serveaux MA, Brunaud L, Reibel N, Quilliot $D$, Ziegler O: Medical follow up after bariatric surgery: Nutritional and drug issues. General recommendations for prevention and treatment of nutritional deficiencies. Diabetes and Metabolism 2009; 35: 544-557.

2. Mechanick JI, Kushner RF, Sugerman $\mathrm{HJ}$, Gonzalez-Campoy JM, Collazo-Clavell ML, Spitz AF, et al: American Association of Clinical Endocrinologists, The Obesity Society, and American Society for Metabolic \& Bariatric Surgery medical guidelines for clinical practice for the perioperative nutritional, metabolic, and nonsurgical support of the bariatric surgery patient. Obesity 2009; 17: 1-70.

3. Rutledge $\mathrm{R}$ : The mini-gastric bypass: Experience with the 1,274 cases. Obes Surg 2001; 11: 276-280.

4. Copăescu C, Munteanu R, Prala N, Turcu FM, Dragomirescu C: Laparoscopic mini gastric bypass for the treatment of morbid obesity. Initial experience. Chirurgia (Bucur) 2004; 99: 529-539.

5. Carbajo M, García-Caballero M, Toledano M, Osorio D, García-Lanza C, Carmona JA: Oneanastomosis gastric bypass by laparoscopy: Results of the first 209 patients. Obes Surg 2005; 15: 398-404.

6. Wang $\mathrm{W}$, Wei $\mathrm{PL}$, Lee $\mathrm{YC}$, Ming-Te Huang, Chong-Chi Chiu, Wei-Jei Lee: Short-term results of laparoscopic mini-gastric bypass. Obes Surg 2005; 15: 648-654.

7. Lee WJ, Yu PJ, Wang W, Chen T, Wei P, Huang M: Laparoscopic Roux-en- $Y$ versus mini-gastric bypass for the treatment of morbid obesity: A prospective randomized controlled clinical trial. Ann Surg 2005; 242: 20-28.

8. Rutledge $\mathrm{R}$, Walsh $\mathrm{T}$ : Continued excellent results with the mini-gastric bypass: Six-year study in 2,410 patients. Obes Surg 2005; 15: 1304-1308.

9. Noun R, Zeidan S, Safa N: Laparoscopic latero-lateral jejuno-jejunostomy as a rescue procedure after complicated mini-gastric bypass. Obes Surg 2006; 16: 1539-1541.

10. Schweiger $C$, Weiss $R$, Keidar A: Effect of different bariatric operations on food tolerance and quality of qating. Obes Surg 2010; 20:1393-1399.

11. Suter M, Calmes JM, Paroz A, Giusti V: A new questionnaire for quick assessment of food tolerance after bariatric surgery. Obes Surg 2007;17: 2-8.

12. De Zwaan M1, Hilbert $A$, Swan-Kremeier $L$, Simonich H, Lancaster K, Howell LM, et al: Comprehensive interview assessment of eating behavior 18-35 months after gastric bypass surgery for morbid obesity. Surg Obes Relat Dis 2010; 6:79-85.

13. Ernst, Martin Thurnheer, Britta Wilm, Bernd Schultes: Differential changes in dietary habits after gastric bypass versus gastric banding operations. Obes Surg 2009; 19: 274-280.

14. Ortega J, Sala C, Flor B, Jiménez E, Escudero MD, Martinezvalls J, et al: Vertical banded gastroplasty converted to Roux-en-Y gastric bypass: little impact on nutritional status after 5-year follow-up. Obes Surg 2004; 14: 638643.

15. Cordera F, Thompson GB, Sarr MG: Unsatisfactory weight loss after vertical banded gastroplasty: Is conversion to RouxenY gastric bypass successful? Surgery 2004; 136: 731-737.

16. Roller J, Provost D: Revision of failed gastric restrictive operations to Roux-en-Y gastric bypass: Impact of multiple prior bariatric operations on outcome. Obes Surg 2006; 16: 865-869.

17. Van Wageningen $B$, Berends FJ, Van Ramshorst $B$, Janssen I $F$ M: Revision of failed gastric banding to Roux-enY gastric bypass. Obes Surg 2006; 16: 137-141.

18. Suter M1, Giusti V, Héraief E, Calmes JM: Band erosion after laparoscopic gastric banding: occurrence and results after conversion to Roux-en-Y gastric bypass. Obes Surg 2004; 14: 381-386. 
19. Noun R, Zeidan S, Riachi E, Abboud B, Chalhoub $V$, Yazigi A: Mini-Gastric bypass for revision of failed primary restrictive procedures: A valuable option. Obes Surg 2007; 17: 684-688.

20. Fisher BL, Buchwald $H$, Clark W, Champion JK, Fox SR, MacDonald KG, et al: Mini-gastric bypass controversy. Obes Surg 2001; 11: 773777.

21. Mason EE, Ito C: Gastric bypass in obesity. Surg Clin North Am 1967; 47:1345-1352.

22. Griffen WO, Young VL, Stevenson CC: A prospective comparison of gastric and jejunoileal bypass procedures for morbid obesity. Ann Surg 1977; 186:500-509.

23. Welvart $\mathrm{K}$, Warnsinck $\mathrm{H}$ : The incidence of carcinoma of the gastric remnant. JSurg Oncol 1982; 21:104-106.

24. Schafer LW, Larson DE, Melton LJ $3^{\text {rd }}$, Higgins JA, Ilstrup DM.: The risk of gastric carcinoma after surgical treatment for benign ulcer disease: a population-based study in Olmsted County, Minnesota. N Eng J Med 1983; 309: 12101213.

25. Hasson LE, Nyren O, Hsing AW, Bergström R, Josefsson S, B.A, et al: The risk of stomach cancer in patients with gastric and duodenal ulcer disease. N Engl J Med 1996; 242-249.
26. Mahawar KK, Jennings N, Brown J, Gupta A, Balupuri S, Small PK: "Mini" gastric bypass: Systemic review of a controvertial procedure. Obesity 2013; 23: 1890-1989.

27. Noun R, Skaff J, Riachi E, Daher R, Antoun NA, Nasr M: One thousand consecutive mini-gastric bypass: Short- and long-term outcome. Obes Surg 2012; 22: 697-703.

28. Brolin RE, Kenler HA, Gorman JH, Cody R P: Long-limb gastric bypass in the superobese: $\mathrm{A}$ prospective randomized study. Ann Surg 1992; 215: 387-395.

29. Pories WJ, Swanson MS, MacDonld KG, Long SB, Morris PG, Brown BM, et al: Who would have thought it? An operation proves to be the most effective therapy for adult-onset diabetes mellitus. Ann Surg 1995; 222: 339-350.

30. MacLean LD, Rhode BM, Nohr CW: Late outcome of isolated gastric bypass. Ann Surg 2000; 231:524-528.

31. Kular KS, Manchanda N, Rutledge R: Analysis of five-year outcomes of sleeve gastrectomy and mini gastric bypass: A report from the Indian Sub-Continent. Obes Surg 2014; 24:17241728.

32. Lee WJ, Ser KH, Lee YC, Tsou JJ, Chen SC, Chen JC: Laparoscopic Roux-en-Y vs minigastric bypass for the treatment of morbid obesity: A 10-year experience. Obes Surg 2012; 22:1827-1834. 